\title{
Do intelectual do caso Dreyfus ao intelectual orgânico: um modelo de análise da trajetória de Vieira Netto (1945-1973)
}

\section{From the Dreyfus case intellectual to the organic intellectual: a model of analysis of Vieira Netto's trajectory (1945-1973)}

\author{
Regis Clemente da Costa* \\ Névio de Campos*
}

\begin{abstract}
RESUMO
Este artigo tem como objetivo compreender alguns aspectos da trajetória de José Rodrigues Vieira Netto a partir do conceito de intelectual nascido no Caso Dreyfus e da noção de intelectual orgânico de Gramsci. Apoia-se, além do conceito de intelectual, em fontes arquivadas pela Delegacia de Ordem Política e Social (DOPS), Projeto Brasil: Nunca Mais Digital, entrevista, publicações da Ordem dos Advogados do Brasil, seccional Paraná (OAB/PR) e em livros de memória. À luz das fontes e do conceito de intelectual orgânico é possível sustentar que a condição de Vieira Netto está ligada ao campo da intelectualidade e a sua inserção na sociedade, pois ele exerceu a função de professor, advogado, promotor público, integrou a Aliança Liberal, presidiu a OAB/PR, militou junto ao Partido Comunista Brasileiro (PCB), elegeu-se deputado estadual no Paraná e atuou nos movimentos sociais. A reverberação dessa militância pode ser percebida nas inúmeras prisões, na perda de mandato como deputado estadual, nas perseguições, torturas, nos processos, Inquéritos Policiais Militares e na aposentadoria compulsória da Universidade Federal do Paraná. Apesar disso, mesmo em contextos políticos e ideológicos adversos, manteve sua militância, defendeu suas ideias, atuando como intelectual orgânico na construção e defesa do projeto societário e formativo comunista no Paraná.

Palavras-chave: Intelectual. Intelectual orgânico. Vieira Netto. Projeto societário comunista no Paraná.
\end{abstract}

*Universidade Estadual de Ponta Grossa. Ponta Grossa, Paraná, Brasil.E-mail: rclementecosta@ yahoo.com.br-https://orcid.org/0000-0002-6914-039X E-mail: ndoutorado@yahoo.com.br-http:// orcid.org/0000-0003-1850-316X 


\begin{abstract}
This paper aims at understanding some aspects of José Rodrigues Vieira Netto's trajectory from the concept of intellectual originated in the Dreyfus Case and Gramsci's notion of an organic intellectual. Apart from the intellectual concept, it is also based on sources filed by the Delegacia de Ordem Política e Social (DOPS) [Political and Social Order Office], Projeto Brasil: Nunca Mais Digital [Brazil Digital Project: Never Again], interview, publication by the Ordem dos Advogados do Brasil, seccional Paraná (OAB/PR), [Brazilian BAR - section Paraná], and memory books. The sources listed and the concept of organic intellectual shed light on the fact that Vieira Netto's condition is linked to the field of intellectuality and his insertion in the society since he was a professor, lawyer, prosecutor, member of the Liberal Alliance, president of OAB/PR, activist in PCB (Brazilian Communist Party), was elected State Deputy in Paraná and acted in social movements. The echoes of his activism can be noticed in the many times he was made prisoner, his disqualification as State Deputy, persecutions, torture sessions, lawsuits, military police investigation, and compulsory retirement from the Federal University of Paraná. Despite these facts, even in adverse political and ideological contexts, he kept his activism, defending his ideas and acting as an organic intellectual in defence of a communist society and formative project in Paraná.
\end{abstract}

Keywords: Intellectual. Organic intellectual. Vieira Netto. Communist Society Project in Paraná

\title{
Introdução
}

Este artigo inscreve-se na História Intelectual e História dos Intelectuais, área pluridisciplinar que "[...] possibilita diferentes enfoques, como o dos contextos de produção de ideias, o dos agentes socioprofissionais e o das correntes de pensamento" (SILVA, 2002, p. 16). Assim sendo, neste texto, pretende-se compreender alguns aspectos da trajetória de José Rodrigues Vieira Netto a partir da acepção de intelectual nascida no Caso Dreyfus e da noção de intelectual orgânico de Gramsci, tomando sua inserção em diferentes frentes de atuação, notadamente sua militância política e docência na Faculdade de Direito da Universidade Federal do Paraná (UFPR).

Vieira Netto nasceu em 1912, em Rio Negro, no Paraná. Filho de Ulysses Falcão Vieira e Carmem Alvarez, foi advogado, professor catedrático da Faculdade de Direito na UFPR, promotor público, deputado estadual no Paraná 
pelo Partido Comunista Brasileiro (PCB), foi fichado pela Delegacia de Ordem Política e Social (DOPS-PR) já no ano de 1944. Exerceu por vários anos a função de conselheiro da Ordem dos Advogados do Brasil, seccional Paraná (OAB/ PR), sendo por dois mandatos presidente dessa instituição no estado. Foi preso em quatro ocasiões, ao longo de sua trajetória. Em todas as prisões as causas estavam relacionadas a sua militância no PCB. Perseguido, teve seus direitos políticos cassados por 10 anos, foi compulsoriamente aposentado da UFPR, em 1964, pela ditadura militar, e monitorado até seu falecimento, em 1973.

A análise de parte da trajetória de Vieira Netto permite inseri-lo na discussão sobre o papel dos intelectuais, cujo recorte está circunscrito ao debate a respeito do papel do intelectual na sociedade, em particular ao período de 1945 a 1973, compreendendo os anos em que se filiou ao PCB (1945) até o seu falecimento (1973). Assim, a partir do conceito de intelectual orgânico problematizamos as fontes documentais que estão nos arquivos da DOPS-PR, disponíveis no Arquivo Público do Paraná e nos arquivos do projeto Brasil: Nunca Mais Digital. Apoia-se também nas publicações que tratam dessa personagem, produzidas pela OAB-PR, em entrevista e em livros de memória.

O surgimento do intelectual como figura social, com relativa autonomia e razão crítica, data do século XVIII, pouco antes do termo ser oficialmente cunhado na sociedade francesa, a partir do Caso Dreyfus, no final do século XIX. A partir desse caso, o termo intelectual ficou publicamente conhecido. Desde então, é tomado como categoria social, sendo uma das ações sinônima de luta contra o poder arbitrário e a defesa de valores universais, como justiça, verdade. No século XX, vários sentidos do papel do intelectual ganham evidência, como indica o artigo de Gisèle Sapiro (2012). Nesse texto, a partir do caso francês, ela explora oito modelos de intervenção política do intelectual, sendo um deles a acepção de intelectual orgânico que ganhou notoriedade nos estudos de Antonio Gramsci. Esse autor, em seus estudos sobre os intelectuais, denominou de intelectual orgânico aquele que, em seu trabalho, vai além da produção do conhecimento científico, artístico, filosófico. Para Gramsci (2001), o saber e a sua disseminação estão relacionados aos processos de organização e de direção das instituições e dos movimentos sociais, no contexto da organização da cultura.

Há um debate permanente para afirmar o que seria a função do intelectual, como bem sistematiza a historiadora Helenice Rodrigues da Silva (2005) ao dizer que em distintas épocas se constituem modelos diferentes de representação do intelectual. Ou seja, a ideia de intelectual é histórica, cabendo ao investigador observar as diferentes definições e escolher aquela que se mostra mais pertinente para analisar uma determinada personagem. Desse modo, ao tratar de parte da trajetória de José Rodrigues Vieira Netto, observamos que o conceito utilizado por Gramsci tem maior fecundidade para explicar sua atuação intelectual. 


\section{O problema do intelectual a partir do Caso Dreyfus}

No século XVIII é possível observar o surgimento do intelectual como figura social. No entanto, é a partir do Caso Dreyfus, no Século XIX, que o termo ganhou reverberação perante a sociedade francesa ${ }^{1}$. Essa afirmação é corroborada por vários pesquisadores e estudiosos da área. Em Bobbio (1997) podemos notar que o nome é relativamente recente, mas o tema é antigo e esses sujeitos são chamados "intelectuais" há cerca de um século, o que não obscurece o fato de que os temas que são postos em discussão, sempre existiram quando se discute o problema dos intelectuais, por mais que o nome pelo qual foram chamados sejam sábios, sapientes, doutos, philosophes, clercs, hommes de lettres, literatos, entre outros. Marcos Antônio Lopes (2003) reforça a discussão de que, no século XVIII, existiam elementos em relação à intervenção dos intelectuais na sociedade e que a existência da palavra intelectual, em sentido recente, certamente não existia no século XVIII, nem sequer um número significativo de eruditos organizados de maneira engajada.

É mesmo um lugar-comum, entre a maior parte dos especialistas, afirmar que os intelectuais apareceram por ocasião do Caso Dreyfus. Essa assertiva é reiterada por Pierre Bourdieu (1996b, p. 380), ao dizer que "os escritores, os artistas e os cientistas afirmaram-se pela primeira vez como intelectuais quando, no momento do Caso Dreyfus, intervieram na vida política com uma autoridade específica assente na pertença ao mundo relativamente autônomo da arte, da ciência e da literatura". O Caso Dreyfus é usado por estudiosos para estabelecer o nascimento dos intelectuais. Conforme Leclerc (2004, p. 9), "a verdade, pelo menos, é que o termo utilizado enquanto rótulo no debate público nasce por ocasião do Caso Dreyfus". Essa situação não representa que em outras épocas inexistiam grupos que se ocupavam das atividades do pensamento, uma vez que, conforme assevera Gisèle Sapiro (2012, p. 20), "se na maior parte das sociedades encontramos um grupo ou categoria de indivíduos exercendo uma função intelectual, como o clero, é somente a partir do século XVIII que emerge na Europa um campo intelectual relativamente autônomo".

A nova terminologia que se difundiu, primeiramente, na França e depois em muitos lugares do mundo, assumiu um sentido bastante peculiar. Carlos Eduardo Vieira (2008, p. 71-72) sustenta que "a intervenção dos cultos na cena pública não é uma inovação do século XIX, porém as condições materiais de

1 Para acompanhar de modo mais detalhado o debate do nascimento do intelectual consultar Névio de Campos (2015) e Carlos Eduardo Vieira (2008). 
organização da cultura nesse período". Essa reflexão de Vieira também pode ser observada em Michel Winock (2000, p. 35) ao afirmar que "o protesto dos intelectuais, que acompanha o clamor de Zola, está marcado por uma vontade de agir que ultrapassa qualquer consideração política". Nessa direção, Sapiro (2012, p. 29) sustenta que "a inovação reside em seu modo de ação coletiva, a petição, manifestação do poder simbólico acumulado de todos os signatários, que é o corolário da reivindicação do papel dos valores intelectuais e do saber na sociedade democrática contra a arbitrariedade e o dogma".

A reflexão anterior pode ser aprofundada na obra "As regras da arte", em particular quando Bourdieu (1996b, p. 155) destaca que a Zola era "necessário produzir uma figura nova, a do intelectual, inventando para o artista uma missão de subversão profética, inseparavelmente intelectual e política, de molde a fazer surgir como uma opção estética, ética e política". A ação de Zola, na interpretação desse sociólogo, deve ser entendida como uma tentativa de garantir uma autonomia semelhante no campo da política. Para ele (1996b, p. 156), "é o que consegue, quando, na altura do Caso Dreyfus, logra importar para dentro do campo político um problema construído segundo os princípios de divisão característicos do campo intelectual e impor a todo o universo social as leis não escritas desse mundo particular". Bourdieu (1996b, p. 156) avança ao afirmar que "é a autonomia do campo intelectual que torna possível o acto inaugural de um escritor que, em nome das normas próprias do campo literário, intervém no campo político, constituindo-se desse modo como intelectual". De modo mais preciso, "o 'J'accuse' é o auge e a consumação de um processo colectivo de emancipação que progressivamente se foi cumprindo no campo de produção cultural" (BOURDIEU, 1996b, p. 156). Assim, "o intelectual constitui-se como tal intervindo no campo político em nome da autonomia e dos valores específicos de um campo de produção cultural que alcançou um elevado grau de independência perante os poderes" (BOURDIEU, 1996b, p. 156, grifos do autor).

Entretanto, as posições dos intelectuais no campo social são ambivalentes e marcadas por diferentes constrangimentos. Por exemplo, ao tratar da Ocupação alemã na França (1940-1944), Sapiro (1999) mostra os processos de heteronomia do campo intelectual, notadamente ao inventariar a quase completa submissão das atividades culturais aos interesses do campo político. Essa situação ambivalente pode ser aproximada da trajetória de Vieira Netto, notadamente ao momento de sua aposentadoria compulsória na UFPR sob alegação de conspirar contra a ordem. Dessa forma, é possível entender essa personagem no interior desse debate, em que a ideia de intelectual é associada ao compromisso civil, cuja atuação é marcada pela defesa de valores considerados universais, sem deixar de gerar fortes resistências das forças do campo político, como veremos no item seguinte. 
Na atuação intelectual, desde o final do século XIX, está presente a disputa por projetos societários, assim como por concepções de formação humana, isto é, de educação das novas gerações. É nesse horizonte que se inscreve a ideia de educação na própria trajetória de Vieira Netto, pois ao opor-se a ditadura militar, ao defender a democracia e liberdade, ao projetar uma nova forma de vida social, ele postula um novo modo de educar os seres humanos. Portanto, não é possível dissociar das ações dos intelectuais a dimensão educativa, aspecto que inclui os espaços formais, como escola e universidade, mas os extrapola à medida que a formação humana ocorre em todos os espaços de relações sociais, como declarava Antonio Gramsci.

\section{Vieira Netto e o conceito de intelectual orgânico}

O intelectual, na perspectiva de Gramsci, está relacionado aos dirigentes e organizadores da cultura. Para Gramsci (2001), a relação do intelectual com a organicidade da sociedade é parte do seu todo, com o diferencial de que esse sujeito tem em suas ações o empenho na elaboração e efetivação de um projeto de sociedade voltado à classe que pertence, de maneira que as concepções teóricas e o conhecimento acadêmico e científico estejam diretamente ligados à atuação na sociedade, mediatizados por um projeto político e cultural.

Ao afirmar que todo grupo social cria para si intelectuais para dar homogeneidade e consciência da própria função, Gramsci (2001) denota que cada classe tem os seus intelectuais, inclusive intelectuais orgânicos, por estarem inseridos no conjunto da sua classe e na elaboração do referido projeto dela mesma. Ainda, nessa perspectiva, Gramsci (2001, p. 18) sustenta que “[...] todos os homens são intelectuais, mas nem todos os homens têm na sociedade a função de intelectuais". Ou seja, para Gramsci, o intelectual apenas se configura como tal, quando está em relação direta com a organização da classe em que está inserido, de modo a intervir nesses espaços de atuação, criando um sistema de ideias em vista da adesão da classe, embasado numa visão de mundo calcada na transformação.

Vale destacar a questão de que o intelectual não se restringe a uma determinada classe, porém o resultado de sua atuação é sim, produto da classe a que pertence e está inserido organicamente. Para Gramsci (2001, p. 53), “[...] não há atividade humana da qual se possa excluir toda intervenção intelectual, não se pode separar o homo faber do homo sapiens". O pensador italiano, ao discutir a questão da terrenalidade do pensamento, relaciona a filosofia da práxis - termo 
utilizado por ele para referir-se ao materialismo histórico - com a concepção do mundo, reforçando a afirmação de que o homo faber não se separa do homo sapiens, bem como fundamentando suas afirmações no que tange à atuação do intelectual orgânico. Esses intelectuais, por sua vez, estão ligados a uma série de intelectuais dessa mesma classe, que apoia os interesses inerentes a si mesma. Gramsci (1999, p. 154) afirma que,

No plano teórico, a filosofia da práxis não se confunde e não se reduz a nenhuma outra filosofia: ela não é original apenas enquanto supera as filosofias precedentes, mas, sobretudo, enquanto abre um caminho inteiramente novo, isto é, renova de cima a baixo o modo de conceber a própria filosofia.

Nesse sentido, ele ressalta a diferença existente entre a filosofia da práxis e as demais filosofias,

Existe, porém, uma diferença fundamental entre a filosofia da práxis e as outras filosofias: as outras ideologias são criações inorgânicas porque contraditórias, porque voltadas para a conciliação de interesses opostos e contraditórios; a sua "historicidade" será breve, já que a contradição aflora após cada evento do qual foram instrumento (GRAMSCI, 1999, p. 388).

Essa compreensão implica que a classe subalterna não aceita passivamente a imposição de uma concepção do mundo. Pelo contrário, elabora a sua própria, pois "de uma maneira consciente e crítica e, portanto, em ligação com este trabalho do próprio cérebro, escolhe a própria esfera de atividade, participa ativamente na produção da história do mundo" (GRAMSCI, 1999, p. 94). Além disso, destaca-se que o intelectual não pode se restringir à eloquência, aos afetos e paixões, mas ele é ativo na sociedade:

[...] inserção ativa na vida prática, como construtor, organizador, 'persuasor permanentemente', já que não apenas orador puro - mas superior ao espírito matemático abstrato; da técnica-trabalho, chega à técnica-ciência e à concepção humanista histórica, sem a qual permanece "especialista" e não se torna "dirigente" (especialista + político) (GRAMSCI, 2001, p. 53). 
Para ele, há um vínculo entre o intelectual orgânico e o partido, e do partido com o intelectual, pois, para alguns grupos sociais, o partido político elabora sua própria categoria de intelectuais orgânicos, formados no processo do grupo social, envolvendo os campos político e filosófico, e não na esfera da técnica produtiva, ou seja, o processo de formação do intelectual no partido se dá numa organicidade entre a ação do partido e a ação do intelectual no partido e na sociedade (GRAMSCI, 2001). Ainda sobre o partido, dentre as várias menções a esse tema, Gramsci aponta que ele desempenha, na sociedade civil, a mesma função do Estado. Porém,

[...] de modo mais vasto e mais sintético, na sociedade política, ou seja, proporciona a soldagem entre intelectuais orgânicos de um dado grupo, o dominante, e intelectuais tradicionais; e esta função é desempenhada pelo partido precisamente na dependência de sua função fundamental, que é a de elaborar os próprios componentes, elementos de um grupo social nascido e desenvolvido como 'econômico', até transformá-los em intelectuais políticos qualificados, dirigentes, organizadores de todas as atividades e funções inerentes ao desenvolvimento orgânico de uma sociedade integral, civil e política (GRAMSCI, 2001, p. 24).

Nesse debate, Régis Debray (1983, p. 273, grifo do autor) aponta que "Gramsci não teria levado tão a sério os intelectuais se não houvesse levado a sério a questão prática do Estado e do poder do Estado, tanto quanto a da organização do partido e do poder no partido". O intelectual está posto no coração do problema, a partir de sua atividade própria, substancial e indispensável. O intelectual não pode constituir uma classe autônoma, pois ele só existe ligado a uma "classe-sujeito" que se encontra inserido no sistema produtivo, como sublinha Debray (1983).

O intelectual orgânico, que atua no partido e é responsável pela elaboração/ execução de um projeto societário, está vinculado também a uma concepção do mundo, ou seja, à construção de uma mudança que é cultural (educacional). A concepção do mundo, para Gramsci, está vinculada à filosofia, não obstante, o intelectual orgânico e o filósofo são os sujeitos do processo político e cultural, pois "[...] o filósofo e pensador não podiam ser destacados do homem político e de partido" (GRAMSCI, 1999, p. 397). Ainda, nesse sentido, 
[...] o verdadeiro filósofo é - e não pode deixar de ser - nada mais do que o político, isto é, o homem ativo que modifica o ambiente, entendido por ambiente o conjunto das relações de que todo indivíduo faz parte (GRAMSCI, 1999, p. 413).

A atuação política do homem ativo está relacionada à modificação da vida societária, destacando-se as práticas culturais que são produzidas e se voltam à compreensão da realidade. O partido é também o articulador de alianças entre as classes trabalhadoras, pois sua função está em atuar na construção e na defesa do projeto hegemônico da classe subalterna. No seio da classe operária terá sido forjada a classe dirigente, o intelectual orgânico dessa classe, como fruto dos processos formativos e educativos. Os intelectuais orgânicos dessa classe, por sua vez, atuarão na organização da cultura, numa luta para transformar a visão de mundo.

A atuação de Vieira Netto na construção do projeto societário e formativo comunista no Paraná pode ser interpretada a partir das discussões de Gramsci, especialmente por sua atuação como advogado, como professor, como militante junto ao PCB e aos movimentos sociais. Ele extrapola os limites da sua atuação meramente profissional de advogado e professor, pois essas atividades jamais estiveram dissociadas de sua militância política e social. Nesse aspecto, no período de análise podemos perceber que Vieira Netto compreendia e assumiu seu papel intelectual em todos os espaços de ação, aproximando-se da definição de Gramsci:

Todo homem, fora de sua profissão, desenvolve uma atividade intelectual qualquer, ou seja, é um "filósofo" um artista, um homem de gosto, participa de uma concepção do mundo, possui uma linha consciente de conduta moral, contribui assim para manter ou para modificar uma concepção do mundo, isto é, para suscitar novas maneiras de pensar (GRAMSCI, 2001, p. 53).

Vieira Netto tem origem familiar ligada à política paranaense. Seu pai foi deputado estadual no Paraná em duas legislaturas (1914-1917, 1935-1936); foi professor da Universidade do Paraná, esteve envolvido em mobilizações no contexto da Era Vargas e foi o fundador da Academia Paranaense de Letras. Observa-se que Vieira Netto encerrava-se nas fileiras de famílias que herdavam capital político, social e cultural. Ele materializa essa tendência à medida que 
frequentou o curso de Ciência Jurídica da Faculdade de Direito do Paraná, passando a exercer atividades no Instituto dos Advogados do Paraná (IAP) e chegando ao mandato de presidente da OAB/PR.

Apesar de suas ligações com as frações da classe dominante, na década de 1940, Vieira Netto se filiou ao PCB, onde militou até o início da década de 1970, quando faleceu. Em 1945, após o fim do Estado Novo, com a legalização do PCB, ele foi candidato a deputado federal, mas não foi eleito. No ano de 1946, candidatou-se a deputado estadual, sendo eleito no pleito realizado em janeiro de 1947. Seu mandato, no entanto, foi curto, pois, novamente, o PCB foi colocado na ilegalidade, em 1948, pelo Presidente Dutra.

A militância de Vieira Netto nessa agremiação partidária continuou, mesmo após o partido ter sido colocado na ilegalidade. Como estratégia de continuidade do projeto do $\mathrm{PCB}$, no contexto da ilegalidade, as candidaturas de comunistas aconteciam em outras legendas e, por vezes, identificavam os candidatos comunistas às suas lideranças de maior expressão, como podemos perceber nas propagandas seguintes: “[...] candidatos de Vieira Netto” (PARANÁ, 1944), conforme consta na ficha individual ${ }^{\circ} 45.992$ e os "[...] candidatos de Prestes" em referência a Luiz Carlos Prestes (PARANÁ, [196?b]. As candidaturas dos comunistas via outras legendas continuaram por vários anos, pois, o PCB só conquistou sua legalidade na década de 1980 .

Ao lado da atividade política, eletiva ou de militância direta em movimentos sociais, Vieira Netto também é conhecido pela atuação docente na UFPR. Ele iniciou na Faculdade de Direito do Paraná como professor de Literatura no curso Pré-Jurídico. Em 1939, atuou como professor de Direito Constitucional e Civil, assim como de Economia Política na Faculdade de Ciências Econômicas do Paraná (VIEIRA NETTO, 1957). Também foi professor de filosofia no Colégio Rio Branco, no início da década de 1940. Há também menções às suas relações com o Colégio Novo Ateneu, conforme registros feitos pela DOPS-PR.

Nos documentos da DOPS-PR (1944), nas ficha n 45.992 (PARANÁ, 1944) e ficha ${ }^{\circ} 45994$ (PARANÁ, [194?a]) sobre Vieira Netto, é possível encontrar o registro de que, no ano de 1944, ele tinha envolvimento com os estudantes do Colégio Liceu Rio Branco e Ginásio Novo Ateneu. No Colégio Liceu Rio Branco, na referida ficha, há menção ao seu vínculo com o Diretor do Colégio, Professor Aníbal Carneiro. O registro em que aparecem essas escolas relata uma manifestação estudantil, no dia em 22 de agosto de 1944, contra o governo brasileiro, naquela ocasião Getúlio Vargas, ao qual teceu duras críticas ao fazer uso da palavra no palanque armado na Avenida João Pessoa (PARANÁ, 1944). No que diz respeito ao envolvimento de Vieira Netto com o Colégio Liceu Rio Branco, é possível observar que "tomou parte, na Conferência realizada pelo Colégio Liceu Rio Branco a respeito de Wendel Wilkie”, de acordo com o 
registro da DOPS-PR - ficha n ${ }^{\circ} 45.992$ (PARANÁ, 1944, p. 2), de 16 de outubro de 1944. Importante dizer que os acontecimentos envolvendo Vieira Netto e a manifestação estudantil no ano de 1944 é o primeiro registro na ficha de Vieira Netto na DOPS-PR.

Seu fichamento na DOPS-PR é datado de 23 de agosto de 1944, conforme consta na ficha $\mathrm{n}^{\circ}$ 45.992, aberta em 29 de setembro de 1944, envolvendo sua participação em comício realizado no dia 22 de agosto, na cidade de Curitiba. Em seu primeiro fichamento na DOPS-PR, consta que:

Por ocasião do comício do dia 22, bem como da passeata organizada pelos Ginásios "Liceu Rio Branco" e "Novo Ateneu", no palanque armado a Avenida João Pessoa, usando a palavra, discursou com violência, atacando os homens do governo brasileiro, criticando o tabelamento e o racionamento de alimentos, bem como sobre a falta de liberdade. Dizendo [sic] textualmente que o único regime de liberdade é o regime da Rússia, que o povo brasileiro está sujeito a restrições absurdas e que nas filas de açúcar só se vê o pobre, pois os abastados têm tudo o que precisam, sem se incomodar (PARANÁ, 1944, p. 2).

A vida política de Vieira Netto não está dissociada de sua atividade docente, embora no exercício estrito das aulas de direito na UFPR ele faça relação dos problemas jurídicos à tradição marxista, tomando as discussões de ordem teórica. Nessa instituição, ele assumiu a docência efetiva no ano de 1957, ao ser aprovado em concurso na Faculdade de Direito, na condição de docente livre e, posteriormente, catedrático de Direito Civil. No entanto, sua atuação de professor durou em torno de 7 anos. Essa breve atuação como professor se deve ao fato de que, após o golpe militar de 1964, foi aberto um processo na UFPR que desencadeou sua aposentadoria compulsória. Esse processo aconteceu sem que Vieira Netto tivesse direito a se defender.

Nos anos em que esteve à frente da Cátedra de Direito Civil na UFPR foi paraninfo de duas turmas de formandos. Em 1960, participou da formatura dos estudantes que lhe renderam homenagem. Na segunda, em 1964, por já estar processado e aposentado pelo golpe que sofrera, tanto dos militares, quanto daqueles que conduziram seu processo interno na UFPR, foi proibido de ser paraninfo e de fazer seu discurso. Como resistência à proibição e denúncia das estruturas que davam guarida às ações do governo militar, Vieira Netto redigiu um texto e o distribuiu aos formandos, cujo discurso é intitulado "Sobre as quatro 
liberdades"2 (PARANÁ, [1964], p. 137-161). Como destacado por Vieira Netto (1964 apud HELM, 2012, p. 304) o texto visava "denunciar à Nação, o clima de intolerância, de servilismo, ignorância e ódios pessoais que, a pretexto de uma revolução, se instalou em algumas universidades brasileiras". Ainda sobre a proibição, quando ele trata da liberdade de dizer, aponta que "decidiram que estou proibido de falar-vos. Assim, não estarei presente a essa festa de vossa formatura" (PARANÁ, [1964], p. 137-161).

Nas suas atividades docentes não deixava de aproximar o direito dos debates do pensamento marxista. Em 1958, por exemplo, Vieira Netto participou de uma conferência sobre marxismo, organizada pelos estudantes da Faculdade de Direito, em que abordou as contribuições de Marx e Engels para a compreensão da história das sociedades, privilegiando as contribuições do método dialético e materialismo histórico. Essa conferência foi publicada na Revista Themis, do Centro Acadêmico Hugo Simas (CAHS), da Faculdade de Direito, em 1958 (VIEIRA NETTO, 1958).

Com o Golpe Militar em 1964 e a instauração da ditadura militar, a relação de Vieira Netto com o CAHS se mantém. Igualmente o posicionamento político do CAHS e dos estudantes de Direito continua, como apontam diversos documentos registrados pela DOPS-PR, dentre eles a Pasta nominada "D.C.E.Federal" (PARANÁ, [196?a]), a Pasta "Manifestos Subversivos" (PARANÁ, [196?b]) e pelo Projeto "Brasil: Nunca Mais", com as pastas 279 e 512 (BRASIL NUNCA MAIS, 2016a) e (BRASIL NUNCA MAIS, 2016d). A participação ativa do CAHS, posterior a 1964, está relacionada, principalmente, às questões relativas à defesa das liberdades, à defesa da participação estudantil nas decisões na UFPR, à luta contra a ditadura militar e contra a repressão, perseguição e prisão de estudantes e professores.

Em manifesto de 29 de setembro de 1967, o CAHS, juntamente com nove Centros Acadêmicos da Universidade Federal do Paraná, o Diretório Central dos Estudantes e a União Paranaense dos Estudantes, se manifesta sobre as prisões de estudantes e intelectuais no Brasil, em especial, na cidade de Curitiba. No manifesto, apontam a incomunicabilidade a que os presos foram submetidos, sem direito à defesa. Dentre as críticas, ressaltam que "o pavor e o medo que os militares querem impor à população traduz claramente os seus ardilosos objetivos e seus envilecidos propósitos de manter a situação atual que interessa tão somente a grupos escusos e alheios ao povo brasileiro" (BRASIL NUNCA MAIS, 2016d) [pastas 512-527]. As prisões efetuadas pelos militares, no ano de 1967, incluíram vários militantes comunistas do Paraná.

$2 \mathrm{O}$ texto "Sobre as quatro liberdades" encontra-se na íntegra nos arquivos da DOPS-PR, na pasta individual sobre José Rodrigues Vieira Netto. 
Vieira Netto estava nesse grupo e ficou preso, incomunicável, por mais de 30 dias (BRASIL NUNCA MAIS, 2016d) [pastas 512-3357].

Como parte de outros posicionamentos do CAHS, podemos citar a abertura de sindicância, feita pela polícia, para apurar a responsabilidade na distribuição de manifesto lançado por vários Diretórios Acadêmicos de Curitiba contra a prisão de militantes. Diante da sindicância, encaminhou-se certidão de antecedentes de várias pessoas, dentre elas, Vieira Netto e Vitório Sorotiuk do CAHS (BRASIL NUNCA MAIS, 2016d) [pastas 512-524].

O envolvimento de Vieira Netto com os estudantes e a defesa de suas causas são mencionadas em relatório do Inquérito Policial Militar (IPM), comandado pelo Capitão Haroldo Souto Carvalho, datado de 13 de outubro de 1964 (BRASIL NUNCA MAIS, 2016b) [pastas 390-889]. Vieira Netto e Amílcar Gigante são apontados como os únicos professores da Universidade Federal do Paraná a se posicionarem em defesa da participação dos estudantes nas instâncias decisórias da Universidade. Esse IPM tinha como finalidade apurar atividades subversivas dos estudantes em Curitiba e incluía a União da Juventude Comunista, o Centro Popular de Cultura, a Juventude Universitária Católica, a Aliança OperárioCamponesa Estudantil e o Instituto Cultural Brasil-Cuba.

A defesa dos estudantes feita por Vieira Netto ocorreu em Assembleia convocada pelo Reitor Flávio Suplicy, após participar, em Brasília, de um Fórum de Reitores, convocado pelo Ministro da Educação Roberto Lyra para discutir a participação de $1 / 3$ dos estudantes nos órgãos diretivos das Universidades. Ao retornar do Fórum dos Reitores, o Conselho Universitário "recepcionou e aplaudiu, por unanimidade, a vitória brilhantemente conquistada pelo seu Reitor, no Fórum de Brasília" (BRASIL NUNCA MAIS, 2016b, p. 874). No entanto, apenas o reconhecimento dessa vitória pelo Conselho Universitário não foi o bastante para o Reitor, que convocou uma Assembleia Universitária a fim de demonstrar a unicidade da UFPR em torno da questão. O resultado não foi tão uníssono como esperava Suplicy. Vieira Netto e Amílcar Gigante votaram contra a posição de Suplicy e dos demais presentes. Ambos ficaram a favor do direito dos estudantes terem $1 / 3$ de representatividade nos órgãos diretivos da Universidade (BRASIL NUNCA MAIS, 2016b, p. 874). A participação de Vieira Netto com os estudantes na greve de 1/3 é mencionada por Noel Sanwais, em depoimento, conforme registro da ficha $\mathrm{n}^{\circ} 45.992$ do DOPS-PR (PARANÁ, 1944).

A ligação de Vieira Netto à intelectualidade está relacionada com sua militância e luta política, desde a juventude. Ao longo de sua trajetória, Vieira Netto se inseriu nos meios em que atuou. Como intelectual, na perspectiva gramsciana, a organicidade de sua atuação se deu, inicialmente, junto à classe dominante, na década de 1930, no contexto da herança familiar. Profissionalmente, 
a carreira de advogado perpassou grande parte de sua trajetória. Nos primeiros anos de sua atuação profissional, abandonou a carreira de Promotor Público e se dedicou à advocacia, constituindo um escritório próprio (VIEIRA NETTO apud ANDRADA, 1974), onde advogou até os anos finais de sua vida.

A atuação profissional de Vieira Netto, no entanto, extrapola as questões meramente profissionais. Desde a juventude, é possível encontrar os registros de sua inserção nos diversos espaços relacionados às questões políticas ou correlacionados à atuação profissional em órgãos de classe, como o Instituto dos Advogados do Paraná e a OAB/PR. Em ambos, exerceu a função de presidente, além de outras atribuições. Sua ligação com a OAB se estendeu até os anos finais de sua vida (HELM, 2012). Nessa entidade, tem sua trajetória reconhecida e foi homenageado em algumas ocasiões. Dentre as homenagens prestadas pela OAB-PR, existe a Medalha José Rodrigues Vieira Netto, a edição da obra biográfica "José Rodrigues Vieira Netto: vida e obra de um grande mestre", de Helm (2012), a obra "O Advogado José Rodrigues Vieira Netto", organizado pela OAB (ANDRADA, 1974). As homenagens constam, ainda, por meio de menções em jornais e obras de memória que contam a história da entidade, tais como "A OAB aos 75 anos: 1932-2007" (ORDEM DOS ADVOGADOS DO BRASIL, 2007); 80 anos OAB: 1932-2012 (ORDEM DOS ADVOGADOS DO BRASIL, 2013); 85 anos OAB: 1932-2017 (ORDEM DOS ADVOGADOS DO BRASIL, 2017).

No bojo de sua atuação é possível encontrar registros de Vieira Netto junto à Aliança Liberal, (VIEIRA NETTO apud ANDRADA, 1974, p. 39) e também junto à União Democrática Nacional (UDN), conforme ficha $\mathrm{n}^{\circ} 45.994$ do DOPS-PR (PARANÁ, [194?a] , p. 6). Nesse registro, é possível notar a relação feita pelos agentes da DOPS-PR de que a militância de Vieira Netto na UDN se dava a partir da corrente comunista. As ações de Vieira Netto junto ao PCB fortalecem a identidade de militante comunista, trazendo-lhe consequências como a cassação de mandato eletivo, cassação de direitos políticos, perseguição, tortura e prisão, ao ponto de ser incluído em vários processos, inclusive no Inquérito Policial Militar $n^{\circ} 709$. O IPM 709 é tido como o maior inquérito realizado pelos militares na ditadura de 1964-1985,

Segundo Rodrigo Czajka (2009), o IPM 709, como também era conhecida a coleção, tratava-se de uma publicação organizada por militares vinculados à Escola Superior de Guerra (ESG). Visava organizar e compilar as informações, as investigações e relatórios contidos no Inquérito Policial Militar $n^{0} 709$, sob 
guarda do Superior Tribunal Militar (STM). O IPM n $709^{3}$ tinha como finalidade primordial apurar as atividades do PCB.

A inclusão de Viera no IPM 709 é compreendida no contexto de atuação dos Agentes da DOPS-PR que desempenhavam o serviço de vigilância e controle ideológico, levado a cabo pela ditadura do Estado Novo. Nesse sentido, pode-se inferir que Vieira Netto inicia sua aproximação com o PCB antes de agosto de 1944, conforme seu primeiro registro na DOPS-PR. O Registro da DOPS-PR datado de Agosto de 1944 (PARANÁ, 1944), portanto, é a apresentação pública de Vieira Netto à sociedade curitibana e paranaense como militante comunista, e um marco oficial de seu rompimento político com a classe dominante.

Antes da legalidade do Partido, em 1945, destaca-se a organização das Células Comunistas e a criação dos Comitês Democráticos Populares, ambos, em número significativo e com rápida expansão pela cidade de Curitiba e pelo interior do estado, que contava com a participação de Vieira Netto. Em meio ao entusiasmo com o crescimento do Partido, as notícias sobre reuniões, comícios, debates, convocações e demais atividades eram publicadas nos jornais Gazeta do Povo, O Dia, Diário da Tarde (PARANÁ, [194?b]), o que fomentava ainda mais a agitação popular em torno dos comunistas e do PCB. Tais atividades destacadas reforçam o prestígio popular de que gozava o PCB no pós-guerra, com os louros da luta antifascista e das alianças que fez em nível nacional.

A trajetória militante de Vieira Netto no PCB, conforme registros encontrados em pastas nos arquivos da DOPS-PR e nos arquivos do Projeto 'Brasil: Nunca Mais', se dava, ainda, em outras frentes, como nas articulações políticas junto às lideranças nacionais do PCB. Nas Pastas Brasil Nunca Mais $n^{\circ}$ $279, \mathrm{n}^{\circ} 390$ e n⿳ 391 verificamos nos depoimentos das testemunhas nos Inquéritos Policiais Militares (IPMs), a recepção de Luiz Carlos Prestes por Vieira Netto em Curitiba. As relações de Vieira Netto com Prestes são citadas no relatório sobre Agliberto Vieira de Oliveira, no IPM 709, feito pelo Ministério da Guerra, I Exército. Observa-se que Vieira Netto, por meio de Agliberto, enviara carta ${ }^{4}$ a Prestes, a qual destaca: "prezado amigo e camarada Prestes... [sic] Recebi, por obséquio do Agliberto seu cartão de felicitações por nossa vitória de classe..." [sic] (BRASIL NUNCA MAIS, 2016a).

A ligação de Vieira Netto com as lideranças nacionais do PCB é reafirmada em outros documentos disponíveis em (BRASIL NUNCA MAIS, 2016c, p. 952), em que os inquiridores questionaram Vieira Netto e suas relações com as

3 O IPM teve como encarregado o próprio coronel Ferdinando de Carvalho, citou os nomes de 971 pessoas entre testemunhas, prontuário dos indiciados que, na edição publicada pela BibliEx, não foram tornados públicos.

4 A carta, segundo o relatório em questão, é datada de fevereiro de 1959. 
lideranças do PCB no Paraná e, também, com lideranças nacionais, como Luiz Carlos Prestes, do PCB e Darcy Ribeiro, que havia sido ministro do Governo João Goulart. Sobre Prestes, Vieira Netto afirmou que esteve em sua companhia, almoçando em uma churrascaria,

onde se reuniu informalmente, um grupo de amigos pessoais e de admiradores de Prestes que, no final deste almoço, o declarante disse algumas palavras, manifestando satisfação de revê-lo depois de muitos anos (BRASIL NUNCA MAIS, 2016c, p. 952).

E sobre Darcy Ribeiro, Vieira Netto afirmou que ele deu uma aula inaugural na Universidade do Paraná, "a convite do magnífico Reitor Flávio Suplicy de Lacerda, que o comparecimento dos professores é obrigatório e se faz debaixo de assinatura de ponto; que o declarante conhece mal e mal o Sr. Darci Ribeiro" (BRASIL NUNCA MAIS, 2016c, p. 954).

Ao longo dos anos 1945 a 1973, período em que esteve vinculado ao PCB, Vieira Netto foi preso em algumas ocasiões, todas relacionadas a sua militância política. Dentre as prisões que Vieira Netto sofreu, em consequência de sua militância política, a primeira é datada de 07 de agosto de 1949, por ocasião da realização do Congresso Pró Paz e Cultura, na cidade de Londrina (PARANÁ, [1949], p. 180). Entre os anos de 1964 e 1973, que corresponde ao início da ditadura militar até o falecimento de Vieira Netto, ele foi preso mais três vezes: em 1964, em 1967 e em 1970, cujas discussões específicas podem ser acessadas na tese de Regis Clemente da Costa (2018).

Nos parágrafos anteriores expusemos alguns acontecimentos da trajetória de Vieira Netto que indicam a pertinência do uso do conceito de intelectual orgânico. A ideia consistiu em mostrar aspectos da militância política dessa personagem paranaense, em que podemos notar sua preocupação na divulgação do projeto societário alinhado ao $\mathrm{PCB}$, assim como sua atenção dispensada à formação de uma nova condição da humanidade, seja via educação escolar (atuação de professor na UFPR), seja via educação não escolar que se dava em todas as suas ações, notadamente no PCB. De modo sintético, é possível ilustrar sua ideia de militância com testamento deixado por ele, escrito de próprio punho, no dia 20 de novembro de 1972. Nele, reitera suas posições políticas, teóricas, ideológicas, sua visão de mundo e realça sua esperança de que o país recuperasse a democracia e a liberdade, usurpadas pela ditadura militar. Dessas relações e da sua visão de mundo se efetivou a atuação num projeto societário de perspectiva transformadora que exigia o conhecimento das condições objetivas 
e subjetivas para tal, aspectos que contemplam horizontes de formação ou educação das novas gerações.

O registro em seu testamento evidencia a defesa do projeto societário ao qual esteve inserido e atuante em sua efetivação. Mais do que isso, registra as gerações futuras um horizonte de expectativa, notadamente na seguinte assertiva: "deposito, como última esperança, que minha Pátria um dia possa livrar-se desse bando de fascistas e abutres que hoje saqueiam a sua liberdade e a sua economia" (VIEIRA NETTO, 1972). A afirmação de Vieira Netto sobre a ditadura militar que estava em vigor, reitera sua crença nas liberdades democráticas e sua contraposição ao regime autoritário que retaliava os direitos individuais e políticos, mas acima de tudo mostrava sua expectativa de que o percurso histórico (devir) resultaria na própria superação do que existia no Brasil. Há, entretanto, em sua percepção da realidade, a conexão a um projeto mais amplo, de maneira que, mesmo ele tendo sido vítima de perseguições, prisões, cassações e processos na justiça militar, mantinha a esperança, sem deixar de expor os males causados a si mesmo. Nesse registro não manifestava amargura, o que revela sua capacidade de entendimento de que lutava pelas grandes causas da humanidade e não por projetos pessoais, como podemos perceber na passagem a seguir: "quanto ao mal que me fizeram ou quiseram fazer, não me importa: não me deram amargura e sim esperança” (VIEIRA NETTO, 1972).

Esses registros compõem as muitas evidências de que Vieira Netto não abandonou suas conviç̧ões que o moveram a exercer a condição de intelectual orgânico. Além de expressar sua posição político-ideológica pela via marxista, manifestou-se de maneira incisiva sobre a conjuntura política e econômica em que o Brasil estava envolvido. Ele destacou suas lutas e as consequências sofridas por suas posições políticas, desde quando se posicionou pela militância no PCB e pela teoria marxista. É, porém, a partir das posições teóricas, políticas e ideológicas e de suas ações protagonizadas que é possível inseri-lo no campo da intelectualidade e do engajamento em torno às causas da justiça e da verdade, numa relação direta com o conceito de intelectual orgânico e em correspondência com todo o debate acerca da figura pública dessa personagem que ganhou visibilidade a partir do Caso Dreyfus. 


\section{Considerações finais}

O surgimento do intelectual como figura social está diretamente ligado ao Caso Dreyfus e à ação pública de artistas, cientistas e escritores contra o Estado pela quebra das normas jurídicas no processo contra o capitão Alfred Dreyfus. Esse acontecimento, conforme Gisèle Sapiro (2018, p. 47, tradução nossa), "teve um papel de catalisação dos intelectuais". Desde então, o termo intelectual ficou publicamente conhecido e passa de adjetivo a substantivo, expandindo-se para diferentes lugares do mundo. $\mathrm{O}$ marco desse posicionamento foi a publicação do manifesto J'accuse (Eu acuso) de Émile Zola, no Jornal L'Aurore, no dia 12 de janeiro de 1898 (ZOLA, 2009).

A partir desse debate que ganhou dimensão mundial, discutimos alguns aspectos da trajetória de Vieira Netto, uma personagem da história do Paraná que, ao imiscuir-se nas trincheiras comunistas, travou suas batalhas no âmbito do PCB e em outras frentes de movimentos sociais. Nesse sentido, dadas as formas de intervenção política dos intelectuais sistematizadas por Gisèle Sapiro (2012), identificamos que a proposição sistematizada nas obras de Gramsci se mostrava de grande pertinência para compreender algumas facetas da trajetória dessa personalidade paranaense. O filósofo italiano associou intelectual a engajamento político, aspecto que justifica o uso desse conceito para problematizar a ação de Vieira Netto. Assim, na condição de intelectual orgânico, Vieira Netto já atuava desde os anos finais da década de 1920, mas se dava junto às frações da classe dominante, cujo pertencimento se originava da base familiar. A partir do ano de 1945, quando se vinculou ao PCB, passou a atuar na perspectiva da classe trabalhadora, permanecendo até o seu falecimento, em 1973.

A guinada ideológica e as lutas sociais/políticas caracterizaram a trajetória de Vieira Netto, notadamente sua ação como intelectual orgânico que buscava contribuir à construção do projeto societário comunista no Paraná. Ele integrou diferentes frentes, exercendo suas atividades de professor e advogado, envolvendo-se e liderando ações no PCB e nos movimentos sociais. A vida de Vieira Netto é ambivalente para recuperar a crítica de Pierre Bourdieu à noção de história de vida. Neste texto, optamos pelo uso de trajetória, pois ela consiste numa "série de posições sucessivamente ocupadas por um mesmo agente, em um espaço ele próprio em devir e submetido a transformações incessantes" (BOURDIEU, 1996a, p. 81, grifo do autor). Pelo exposto, este texto privilegiou os anos entre 1945 e 1973, cujo período está circunscrito à sua filiação ao PCB (1945) e às lutas em defesa de sua proposta societária e formativa, encerrada apenas em 1973, com o seu falecimento. 
Vieira Netto exerceu a função de intelectual, pois manteve uma atuação para além do seu trabalho que não se esgotou na produção do conhecimento teórico no campo do Direito. Ele foi um intelectual marcado pela práxis. Dessa feita, tais ações encontram guarida nos processos de organização e de direção das instituições e dos movimentos sociais, no contexto da organização da cultura, como acentua a discussão de Gramsci (2001). A resistência democrática do PCB, pós-1964, seguiu as posições tomadas anteriormente pelo partido que, desde a legalização em 1945, pautou-se pela via da disputa eleitoral, lançando candidatos aos pleitos municipais, estaduais e federal, tanto no executivo como legislativo. No entanto, as ações do partido não estavam restritas às disputas eleitorais, como evidenciam os aspectos aludidos da vida de Vieira Netto.

Ele não viveu para ver o Brasil conquistar as liberdades que ele tanto defendeu, pois faleceu em 1973, quando o país ainda estava sob comando dos militares. No ano de 1985, teve fim a ditadura militar no Brasil. Em 1988, o país conquistou sua nova Constituição Federal (BRASIL, 1988). Em 1989, aconteceu a primeira eleição presidencial com o voto de todos os cidadãos brasileiros. Na Constituição de 1988 se encontram garantidos os direitos civis, políticos, sociais e culturais, destacando-se diversas menções à importância da democracia e da educação. Portanto, em razão das lutas de pessoas como Vieira Netto, que pagaram um alto tributo para defender a democracia e outros tantos direitos, é que a nossa geração vive sob o regime democrático e a afirmação de inúmeros direitos formalizados na Carta Magna. É nesse sentido, mais uma vez, que se reforça o sentido conferido aos intelectuais como categorias sociais que se inserem em sua realidade concreta na defesa de valores considerados universais, de grandes causas da sociedade, como justiça, verdade, liberdades, igualdade, democracia e educação.

\section{REFERÊNCIAS}

ANDRADA, Fernandino Caldeira de. Discursos. Discurso pronunciado na seção solene in memoriam do Prof. Vieira Netto, promovida pela OAB-PR no dia 29 de maio de 1973. In: Ordem dos Advogados do Brasil seção Paraná. O Advogado José Rodrigues Vieira Netto. [Curitiba: [s. n.], 1974.

BOBBIO, Norberto. Os intelectuais e o poder: dúvidas e opções dos homens de cultura na sociedade contemporânea. São Paulo: Unesp, 1997. 
BOURDIEU, Pierre. A ilusão biográfica. In: BOURDIEU, Pierre. Razões práticas: sobre a teoria da ação. Campinas, SP: Papirus, 1996a. p. 74-82.

BOURDIEU, Pierre. As regras da arte: génese e estrutura do campo literário. Lisboa: Presença, 1996b.

BRASIL. [Constituição (1988)]. Constituição da República Federativa do Brasil de 1988. Brasília, DF: Presidência da República, [2020]. Disponível em: http://www.planalto.gov. br/ccivil_03/constituicao/constituicao.htm. Acesso em: 16 jul. 2021.

BRASIL NUNCA MAIS. Projeto Brasil: Nunca Mais. Pasta 279. São Paulo, 2016 a. Disponível em: http://bnmdigital.mpf.mp.br/DocReader/BIB_03/120711. Acesso em: 16 jul. 2021.

BRASIL NUNCA MAIS. Projeto Brasil: Nunca Mais. Pasta 390. São Paulo, 2016 b. Disponível em: http://bnmdigital.mpf.mp.br/DocReader/BIB_04/59667. Acesso em: 20 maio 2018 .

BRASIL NUNCA MAIS. Projeto Brasil: Nunca Mais. Pasta 391. São Paulo, 2016c. Disponível em: http://bnmdigital.mpf.mp.br/DocReader/BIB_04/63481. Acesso em: 15 maio 2018.

BRASIL NUNCA MAIS. Projeto Brasil: Nunca Mais. Pasta 512. São Paulo, 2016 d. Disponível em: http://bnmdigital.mpf.mp.br/DocReader/BIB_06/1643. Acesso em: 10 fev. 2018.

CAMPOS, Névio de. História intelectual e história cultural: um recorte em Roger Chartier. Revista Eletrônica Documento/Monumento, Cuiabá, v. 16, p. 94-122, 2015. Disponível em: https://www.ufmt.br/ndihr/revista/revistas-anteriores/revista-dm-16. pdf. Acesso em: 13 maio 2021.

COSTA, Regis Clemente da. José Rodrigues Vieira Netto: intelectual orgânico, professor brilhante, advogado perseguido, cidadão sem direitos (1945-1973). 2018. 375 f. Tese (Doutorado em Educação) - Universidade Estadual de Ponta Grossa, Ponta Grossa, Paraná, 2018.

CZAJKA, Rodrigo. Praticando delitos, formando opinião: intelectuais, comunismo e repressão no Brasil (1958-1968). 2009. 388 f. Tese (Doutorado em Sociologia) Universidade Estadual de Campinas, Campinas, 2009.

DEBRAY, Régis. O escriba: gênese do político. Rio de Janeiro: Retour, 1983.

GRAMSCI, Antonio. Cadernos do cárcere. Rio de Janeiro: Civilização Brasileira, 1999. v. 1.

GRAMSCI, Antonio. Cadernos do cárcere. Rio de Janeiro: Civilização Brasileira, 2001. v. 2.

HELM, Cecília Maria Vieira. José Rodrigues Vieira Netto: a vida e o trabalho de um grande mestre. Curitiba: OAB, 2012. 
LECLERC, Gerard. Sociologia dos intelectuais. São Leopoldo: Unisinos, 2004.

LOPES, Marcos Antônio. Pena e espada: o nascimento do intelectual. In: LOPES, Marcos Antônio (org.). Grandes nomes da história intelectual. São Paulo: Contexto, 2003. p. 39-48.

ORDEM DOS ADVOGADOS DO BRASIL (Seção do Paraná). OAB Paraná - 1932 2007: a OAB Paraná aos 75 anos. Curitiba: Serzegraf, 2007.

ORDEM DOS ADVOGADOS DO BRASIL (Seção do Paraná). 80 anos OAB: 19322012. Curitiba: Midiograf, 2012.

ORDEM DOS ADVOGADOS DO BRASIL (Seção do Paraná). 85 anos OAB: 19322017. Curitiba: Hellograf Artes Gráficas, 2017.

PARANÁ. Secretaria da Segurança Pública. Delegacia de Ordem Política e Social (DOPS-PR). José Rodrigues Vieira Netto. Ficha individual nº 45.994. Curitiba, [194?a].

PARANÁ. Secretaria da Segurança Pública. Delegacia de Ordem Política e Social (DOPS-PR). Comitê Comunista Central da Capital. Código da pasta BR.PRAPPR. PB004.PT264.29. Curitiba, [194?b].

PARANÁ. Secretaria da Segurança Pública. Delegacia de Ordem Política e Social (DOPS-PR). José Rodrigues Vieira Netto. Ficha individual nº 45.992. Curitiba, 1944.

PARANÁ. Secretaria da Segurança Pública. Delegacia de Ordem Política e Social (DOPSPR). Congresso Pró-Paz. Código da pasta BR.PRAPPR.PB004.PT326. Curitiba, 1949.

PARANÁ. Secretaria da Segurança Pública. Delegacia de Ordem Política e Social (DOPSPR). D.C.E.-Federal. Código da pasta BR.PRAPPR.PB004.PT742.84. Curitiba, [196?a].

PARANÁ. Secretaria da Segurança Pública. Delegacia de Ordem Política e Social (DOPS-PR). Manifestos Subversivos. Código da pasta BR.PRAPPR.PB004.PT1306.152. Curitiba, [196?b].

PARANÁ. Secretaria da Segurança Pública. Delegacia de Ordem Política e Social (DOPS-PR). José Rodrigues Vieira Netto. PI 2194.400 (Número da pasta individual). Curitiba, 1964.

PARANÁ. Secretaria da Segurança Pública. Delegacia de Ordem Política e Social (DOPS-PR). Código da pasta BR.PRAPPR.PB004.PT780a.89. Documentos da DOPS Antigos Pasta 1. Curitiba, 1966.

SAPIRO, Gisèle. La guerre des écrivains (1940-1953). Paris: Fayard, 1999.

SAPIRO, Gisèle. Les écrivains et la politique en France: de l'Affaire Dreyfus à la guerre d'Algérie. Paris: Seuil, 2018.

SAPIRO, Gisèle. Modelos de intervenção política dos intelectuais: o caso francês. Revista Pós Ciências Sociais, São Luís, v. 9, n. 17, p. 19-50, 2012.

SILVA, Helenice Rodrigues da. Fragmentos da história intelectual: entre questionamentos e perspectivas. Campinas: Papirus, 2002. 
SILVA, Helenice Rodrigues da. O intelectual no campo cultural francês: do Caso Dreyfus aos tempos atuais. Varia Historia, Belo Horizonte, v. 21, n. 34, p. 395-413, jul. 2005.

VIEIRA, Carlos Eduardo. Intelligentsia e intelectuais: sentidos, conceitos e possibilidades para a história intelectual. Revista Brasileira de História da Educação, Maringá, n. 16, p. 63-86, jan./abr. 2008.

VIEIRA NETTO, José Rodrigues. Escrito de testamento que faz José Rodrigues Vieira Netto. Curitiba: [s.n.], 1972.

VIEIRA NETTO, José Rodrigues. Posse e domínio da herança. Curitiba: Litero Técnica, 1957.

WINOCK, Michel. O século dos intelectuais. Rio de Janeiro: Bertrand Brasil, 2000.

ZOLA, Émile. J'accuse: a verdade em marcha. Porto Alegre: L\&PM, 2009.

Texto recebido em 27/04/2020.

Texto aprovado em 17/05/2021. 